\title{
Biometrical, biological, biochemical and molecular characteristics of Meloidogyne incognita isolates and related species
}

\author{
Marcilene Fernandes Almeida dos Santos • \\ Cleber Furlanetto • Maria Rita Alves Almeida • \\ Marina Dechechi Gomes Carneiro • \\ Fabiane Castro Mota • \\ Ana Cristina Meneses Mendes Gomes • \\ Natália Orrú Reis Silveira • \\ Joelma Gardênia Pereira Silva • \\ Philippe Castagnone-Sereno • \\ Myrian Silvana Tigano • \\ Regina Maria Dechechi Gomes Carneiro
}

Accepted: 31 May 2012 /Published online: 25 September 2012

(C) KNPV 2012

\begin{abstract}
Meloidogyne incognita is one of the most polyphagous species of root-knot nematodes occurring in Brazil and worldwide. Eight M. incognita isolates were studied, representing two enzymatic phenotypes (esterase and malate desydrogenase: I1/N1, I2/N1) and four cryptic Meloidogyne sp.1 (S2/N1) isolates, representing one cytological type $(3 \mathrm{n}=40-46)$. Three $M$. hispanica isolates $(\mathrm{Hi} 3 / \mathrm{N} 1,2 \mathrm{n}=32-36)$ and two of an atypical Meloidogyne sp.2 (S2a/N3, 3n=40-44) were
\end{abstract}

M. F. A. dos Santos • M. R. A. Almeida •

M. D. G. Carneiro - F. C. Mota - A. C. M. M. Gomes

N. O. R. Silveira • J. G. P. Silva • M. S. Tigano

R. M. D. G. Carneiro ( $\square)$

EMBRAPA-Recursos Genéticos e Biotecnologia,

Brasília DF 70849-970, Brazil

e-mail: recar@cenargen.embrapa.br

M. F. A. dos Santos • C. Furlanetto - J. G. P. Silva

Departamento de Fitopatologia, Universidade de Brasília,

Brasília DF 70910-900, Brazil

P. Castagnone-Sereno

INRA-UMR1355, UNSA, CNRS UMR7354,

Institut Sophia Agrobiotech,

400 route des Chappes, BP167,

06903 Sophia Antipolis, Frances included in this study for comparison. All isolates were tested with three $M$. incognita-specific molecular markers. The primer pairs $\mathrm{B} 06 \mathrm{~F} / \mathrm{R}, \mathrm{miF} / \mathrm{R}$ and incK14F/R amplified three species-specific fragments of 1,200 bp, $955 \mathrm{bp}$ and $399 \mathrm{bp}$, respectively for $M$. incognita and Meloidogyne sp.1 isolates. No amplification occurred in the M. hispanica and Meloidogyne sp.2 isolates, except with primers $\mathrm{miF} / \mathrm{R}(1,650 \mathrm{bp})$. The genetic variability of the Meloidogyne spp. isolates was evaluated, using RAPD and ISSR markers. The phylogenetic analyses revealed two strongly supported monophyletic clades: clade I, consisting of $M$. hispanica and the atypical Meloidogyne sp.2 isolates, and clade II, clustering together all M. incognita and the Meloidogyne sp.1 isolates. Considering the biometrical, cytological and molecular approaches, it was possible to conclude that the isolates with three enzymatic phenotypes (I1/N1, I2/N1 and S2/N1) presented the characteristics described for $M$. incognita. Some correlations were detected between the isozymatic phenotypes and the tree topology (S2a/N3, Hi3/N1, I1/N1, S2/N1), but no strict correlation could be observed for the phenotype I2/N1 and one isolate of S2/N1. Morphologically, the Msp.2 isolates differ from M. incognita and $M$. 
hispanica by the female stylet features presenting straight cone tip and round pear shaped knobs, posteriorly sloping. The results of this study suggested that the Msp. 2 isolates with phenotypes S2aN3 belong to a new or an unidentified species closely related to $M$. hispanica.

Keywords Esterase phenotypes - Meloidogyne hispanica $\cdot$ Molecular markers $\cdot$ Root-knot nematodes

\section{Introduction}

Root-knot nematodes, Meloidogyne spp., are among the most destructive plant-parasitic nematodes. Studies of intraspecific variability of Meloidogyne spp. populations are essential when genetic resistance and crop rotation are considered the most appropriate control strategies (Carneiro et al. 2005b)

Meloidogyne incognita (Kofoid \& White) Chitwood is considered to be one of the major Meloidogyne species due to its worldwide economic importance. It is commonly encountered in tropical regions and in temperate regions restricted to glasshouses (Karssen and Moens 2006). According to the 'North Carolina Host Test', $M$. incognita is made up of four host races (Hartman and Sasser 1985). Populations of all four races reproduce on pepper, watermelon and tomato, but they vary in their response to tobacco and cotton. Detailed morphological investigations of some populations from two cytological and four physiological host races demonstrated that all populations of $M$. incognita were sufficiently morphologically similar to be considered as one taxonomic unit (Eisenback and Triantaphyllou 1991). It is considered a poorly variable species both cytologically and molecularly (Triantaphyllou 1985a; Castagnone-Sereno et al. 1994; Blok et al. 1997; Semblat et al. 1998). Two phenotypes of esterase (EST) activity commonly occur (I1 and I2) however, an atypical esterase pattern (S1/S2) from coffee was also described for M. incognita (Oliveira et al. 2006; Blok and Powers 2009). The malate-dehydrogenase (MDH) phenotype N1 is characteristic of all populations studied (Esbenshade and Triantaphyllou 1985; Carneiro et al. 2000; 2004; Castro et al. 2003; Cofcewicz et al. 2004; Medina et al. 2006).

In surveys carried out in Brazil and Guadeloupe on different crops including coffee, banana, soybean and fig, nematodes harboured the atypical S1/N1/S2/N1 and $\mathrm{B} 2 / \mathrm{N} 3$ phenotypes that were considered as cryptic species (Castro et al. 2003; Cofcewicz et al. 2004, 2005; Carneiro et al. 2005b; Medina et al. 2006). In the intergenic region of mitochondrial DNA sequences, the tree showed the isolate $\mathrm{S} 2 / \mathrm{N} 1$ (35) to be a sister taxon to $M$. incognita, with $89-79 \%$ bootstrap support (Tigano et al. 2005).

Cytologically, the majority of the populations from this species that have been studied have a predominant triploid form, with $3 n=40-46$ chromosomes or a rare diploid form with $2 n=32-36$ (Triantaphyllou 1981). Despite reproducing by mitotic parthenogenesis, $M$. incognita has the capacity to adapt easily to unfavourable abiotic or biotic environmental conditions (CastagnoneSereno 2006). Based on PCR-RAPD analysis, $M$. incognita isolates showed a low intraspecific variability, congruent with isozyme phenotypes. In particular, the I1N1 and I2N1 phenotypes clustered together with $100 \%$ bootstrap support (Randig et al. 2002; Carneiro et al. 2004). These results agree with previous molecular analyses (Castagnone-Sereno et al. 1994; Blok et al. 1997; Semblat et al. 1998). Nevertheless, the variability of some isolates of $M$. incognita presenting different esterase phenotype (I1, I2 and S2) was expressed in their pathogenicity on Coffea spp. Recent studies showed that $C$. arabica cultivars were susceptible to $M$. incognita isolates (Mi1 and Mi4), with Mi1 (I1) from São Paulo State being more aggressive than Mi4 (I2) from Paraná State (Muniz et al. 2009). The opposite was observed for C. canephora 'Conilon'clonal cultivars (Carneiro et al. 2009). The Msp1 isolate (S2) collected from coffee in Garça, showed low aggressiveness to C. arabica genotypes in greenhouse and field conditions (Muniz et al. 2009).

In further studies, RAPD fragments were transformed into Sequence Characterised-Amplified Region (SCAR) markers, and three specific markers (incB06F/R, incK14F/R, miF/R) were developed for $M$. incognita using a few isolates of this species (Zijlstra et al. 2000; Randig et al. 2002; Meng et al. 2004).

It is very difficult to differentiate $M$. hispanica Hirschmann 1986 from M. incognita and M. arenaria, using morphological and biological approaches. Recently, molecular analyses of rDNA regions (18 S, ITS1-5.8 S-ITS2 and D2-D3 of 28 S) showed identical sequences for $M$. hispanica isolates from Brazil, Portugal and Spain. Maximum Parsimony analysis of the three rDNA regions and the species-specific PCR demonstrated the differentiation of $M$. hispanica from other root-knot nematode species (Landa et al. 2008). 
The variability of $M$. incognita isolates, using several tools together, has never been studied. Previous works integrated one or two techniques and were carried out with few isolates (Castagnone-Sereno et al. 1994; Blok et al. 1997; Semblat et al. 1998; Randig et al. 2002; Carneiro et al. 2004). In this study, the genetic variability and relationships of eight Brazilian $M$. incognita isolates, six acryptic Meloidogyne spp. isolates and three of $M$. hispanica, obtained from different crops and geographical regions, were compared using isozymatic, biometrical, biological, and molecular parameters. Another aim of this study was to validate the three previously described M. incognita specific SCAR markers on isolates exhibiting different esterase phenotypes and belonging to various host races.

\section{Material and methods}

\section{Nematode isolates}

Eight isolates were previously identified using esterase phenotypes (Carneiro and Almeida 2001) as M. incognita, three as $M$. hispanica and six as unidentified isolates. Meloidogyne javanica and M. hapla isolates were used as reference isolates in biochemical studies and $M$. javanica as an outgroup in phylogenetic analyses (Table 1). All the isolates were multiplied under greenhouse conditions on tomato plants (Solanum lycopersicum L.) cv. Santa Clara.

\section{Isozyme analyses}

Isozyme characterisations were done for EST and MDH using polyacrylamide gel electrophoresis according to Carneiro and Almeida (2001). Protein extracts from five young egg-laying females from pure isolates of $M$. javanica and $M$. hapla were included in each gel as reference phenotypes for EST and MDH characterisation, respectively. Esterase phenotypes were designated by letters suggesting the nematode species followed by a number indicative of the number of bands (Esbenshade and Triantaphyllou 1985, 1990).

\section{Biometrical studies}

Biometrical studies were conducted on adult males and females and second-stage juveniles (J2) of the 14 Meloidogyne spp. isolates studied. Adult males and $\mathrm{J} 2$ were obtained according to Carneiro et al. (2008b), killed in cold $\left(5^{\circ} \mathrm{C}\right) 2 \%$ formalin (gentle death), and measured immediately under light microscopy (LM). Morphometric studies were done using the measurements suggested by Eisenback and Hunt (2009). Perineal patterns were cut from live young females in $45 \%$ lactic acid and mounted in glycerin (Taylor and Netscher 1974). Freshly hatched J2 and males and stylets of males and females were prepared for scanning electron microscope (SEM) according to Eisenback and Triantaphyllou (1991). Specimens were viewed and photographed with a Zeiss DSM-962. At least 30 specimens of each life-stage were examined.

\section{Biological studies}

Cytogenetic studies were carried out with a propionic orcein stained method described in details by Triantaphyllou (1985b) with fixation, hydrolysis, staining and mounting in sequence (17 isolates). The North Carolina differential host range test was performed for 14 isolates according to Hartman and Sasser (1985).

\section{Molecular studies}

DNA extraction: Eggs were extracted from infected roots of tomato, according to McClure et al. (1973) and stored at $-80{ }^{\circ} \mathrm{C}$, until use. For each nematode isolate, genomic DNA was extracted from 200 to $300 \mu \mathrm{l}$ of eggs. Briefly, eggs were crushed in liquid nitrogen with mortar and pestle, and DNA was extracted from the resulting powder according to a classical phenol-chloroform procedure (Randig et al. 2002).

SCAR analysis: PCR assays were carried out using the $M$. incognita specific SCAR primers incB06F/R, incK14F/R and miF/R (Zijlstra et al. 2000; Randig et al. 2002; Meng et al. 2004). The PCR reactions were performed in $25 \mu \mathrm{l}$ volume, containing $5 \mathrm{ng}$ of total genomic DNA, $0.5 \mathrm{U}$ of Taq polymerase (Invitrogen), $1 \mathrm{x}$ Taq polymerase reaction buffer, $200 \mu \mathrm{M}$ of each dNTP (Pharmacia Biotec), $0.05 \mu \mathrm{M}$ of $\mathrm{MgCl}_{2}$ and $8 \mu \mathrm{M}$ of each primer (Life Technologies). The amplifications were performed using the PTC-100 programmable thermal controller (MJ Research), and the PCR conditions were the same as those used by Zijlstra et al. (2000), Randig et al. (2002) and Meng et al. (2004), respectively. 
Table 1 Meloidogyne spp. isolates, geographic origin, host plants, enzyme phenotypes and chromosome number

\begin{tabular}{|c|c|c|c|c|}
\hline $\begin{array}{l}\text { Species isolate } \\
\text { code (race) }\end{array}$ & $\begin{array}{l}\text { Geographic } \\
\text { origin }\end{array}$ & Host plant & $\begin{array}{l}\text { EST/MDH } \\
\text { phenotypes }\end{array}$ & $\begin{array}{l}\text { Chromosome } \\
\text { number }\end{array}$ \\
\hline \multicolumn{5}{|l|}{ M. incognita } \\
\hline Mi 1 (race 1) & Avilândia, SP*, Brazil & Coffea arabica $\mathrm{L}$. & $\mathrm{I} 1 / \mathrm{N} 1$ & $42-46$ \\
\hline Mi 2 (race 2) & Londrina, PR, Brazil & C. arabica $\mathrm{L}$. & $\mathrm{I} 1 / \mathrm{N} 1$ & $40-44$ \\
\hline Mi 3 (race 3) & Londrina, PR, Brazil & C. arabica $\mathrm{L}$. & $\mathrm{I} 1 / \mathrm{N} 1$ & $44-46$ \\
\hline Mi 4 (race 3) & Londrina, PR, Brazil & Gossypium hirsutum L. & $\mathrm{I} 2 / \mathrm{N} 1$ & $42-46$ \\
\hline Mi 5 ( race 4) & Jacuípe, PE, Brazil & Curcubita pepo L. & $\mathrm{I} 2 / \mathrm{N} 1$ & $40-44$ \\
\hline Mi 6 (race 3) & Santa Cruz, RS, Brazil & Nicotiana tabacum $L$. & $\mathrm{I} 2 / \mathrm{N} 1$ & $44-46$ \\
\hline Mi 7 (race 2) & Brasilia, DF, Brazil & Solanum lycopersicum L. & I2/N1 & $44-46$ \\
\hline Mi 8 (race 1) & Ijuí, RS, Brazil & S. lycopersicum L. & $\mathrm{I} 2 / \mathrm{N} 1$ & $44-46$ \\
\hline \multicolumn{5}{|c|}{ Meloidogyne sp.1 (=M. incognita) } \\
\hline Msp.1 9 (race 2) & Dindorama, GO, Brazil & Glycine $\max (\mathrm{L}$.$) Merr$ & $\mathrm{S} 2 / \mathrm{N} 1$ & $44-46$ \\
\hline Msp.1 10 (race 3) & Pelotas, RS, Brazil & Ficus carica $\mathrm{L}$. & $\mathrm{S} 2 / \mathrm{N} 1$ & $40-44$ \\
\hline Msp.1 11 (race 3) & Garça, SP, Brazil & C. arabica $\mathrm{L}$. & $\mathrm{S} 2 / \mathrm{N} 1$ & $44-46$ \\
\hline Msp.1 12 (race 1) & Cajati, SP, Brazil & Musa sp. & $\mathrm{S} 2 / \mathrm{N} 1$ & $40-44$ \\
\hline \multicolumn{5}{|l|}{ Meloidogyne sp.2 } \\
\hline Msp2.13 (race 2) & Martinique & Musa sp. & $\mathrm{S} 2 \mathrm{a} / \mathrm{N} 3$ & $40-44$ \\
\hline Mp2. 14 (race 2) & Martinique & Saccharum officinarum L. & $\mathrm{S} 2 \mathrm{a} / \mathrm{N} 3$ & $40-44$ \\
\hline \multicolumn{5}{|l|}{ M. hispanica } \\
\hline Mhi 15 & Jacuípe, PE, Brazil & Curcubita pepo L. & $\mathrm{Hi3/N1}$ & $32-36$ \\
\hline Mhi 16 & Tabuleiros Costeiros, PE, Brazil & S. officinarum L. & $\mathrm{Hi3} / \mathrm{N} 1$ & $32-36$ \\
\hline Mhi 17 & Seville, Spain & Prunus persica (L.) Batsch & $\mathrm{Hi3} / \mathrm{N} 1$ & $32-36$ \\
\hline \multicolumn{5}{|l|}{ M. javanica } \\
\hline Mj18 & Petrolina, PE, Brazil & S. lycopersicum L. & $\mathrm{J} 3 / \mathrm{N} 1$ & - \\
\hline \multicolumn{5}{|l|}{ M. hapla } \\
\hline Mh19 & Farroupilha, RS, Brazil & $\begin{array}{l}\text { Actinidia deliciosa (Chevalier) } \\
\text { Liang \& Ferguson }\end{array}$ & $\mathrm{H} 1 / \mathrm{H} 1$ & - \\
\hline
\end{tabular}

* Brazilian states: SP, São Paulo, PR, Paraná, RS, Rio Grande do Sul, PE, Pernambuco, DF, Distrito Federal, GO, Goiás.

RAPD analysis: The RAPD-PCR reactions were performed in $25 \mu \mathrm{l}$ volume, containing $6 \mathrm{ng}$ of total genomic DNA, $1 \mathrm{U}$ of Taq polymerase (Invitrogen), 1x Taq polymerase reaction buffer, $200 \mu \mathrm{M}$ of each dNTP (Pharmacia Biotec), and $8 \mu \mathrm{M}$ of each primer (Operon Technologies or Invitrogen Life Technologies) (Reference). Thirty-five 10-mer oligonucleotide primers were used in the analysis: A4, A13, A14, A18, AB9, AB10, AB11, AB12, AB17, B6, B18, B20, C7, C9, C16, C18, D5, D8, G2, G5, G6, G13, J10, J19, K4, K6, K7, K16, K20, L8, M20, R5, R7, R8 and R12. The cycling conditions were as follows: $5 \mathrm{~min}$ at $94{ }^{\circ} \mathrm{C} ; 40$ cycles of $30 \mathrm{~s}$ at $94^{\circ} \mathrm{C}, 45 \mathrm{~s}$ at $36^{\circ} \mathrm{C}$ and $2 \mathrm{~min}$ at $70{ }^{\circ} \mathrm{C}$; and a final elongation of $10 \mathrm{~min}$ at $70{ }^{\circ} \mathrm{C}$.

ISSR analysis: The ISSR-PCR reactions were performed in $25 \mu \mathrm{l}$ volume, containing $3 \mathrm{ng}$ of genomic
DNA, 1 U Taq DNA polymerase (Invitrogen), 1x Taq polymerase reaction buffer, $0.2 \mathrm{mM}$ of each dNTP (Pharmacia Biotec), and $15 \mathrm{ng}$ of each primer. ISSR primers (Integrated DNA Technologies, Inc.) were $(\mathrm{GA})_{8} \mathrm{C},(\mathrm{AC})_{8} \mathrm{G},(\mathrm{CA})_{8} \mathrm{G},(\mathrm{CCA})_{5},(\mathrm{GA})_{7} \mathrm{CA}$, $(\mathrm{CT})_{8} \mathrm{GG},(\mathrm{CA})_{7} \mathrm{CTCTT},(\mathrm{AG})_{8} \mathrm{Y}$ and $(\mathrm{GACA})_{4}$. The amplifications were carried out in a PTC-100 programmable thermal controller (MJ Research), as described by Lax et al. (2007). Amplification products for both RAPD and ISSR were separated in a $1.5 \%$ agarose gel, stained with ethidium bromide $(0.3 \mu \mathrm{g} \mathrm{ml})$ and visualized under UV light. Each experiment was replicated at least twice.

Phylogenetic analyses: RAPD and ISSR bands were scored for presence (1) or absence (0), and transformed into a $0 / 1$ binary character matrix. Experiments were 
repeated at least once, and fragments that could not be scored unambiguously were excluded from the data. Three different phylogenetic methods, UPGMA, Maximum Parsimony and Bayesian inference, were used on three datasets: ISSR, RAPD, and the combined set of both. UPGMA and maximum parsimony analyses were performed using PAUP* v 4.0 (Swofford 2002), with mean character difference and TBR branchswapping options, respectively. One thousand bootstrap replicates were performed to test the robustness of both the UPGMA and Maximum Parsimony output trees (Felsenstein 1985). Bayesian phylogenetic analysis was conducted with MrBayes v3.1 (Ronquist and Huelsenbeck 2003) using a binary F81-like model, with a total of $1,000,000$ runs.

\section{Results}

Isozyme analysis

Two phenotypes for EST activity were recognised in the eight $M$. incognita isolates. The phenotype I1 (Rm: 1.0) was detected in isolates Mi1, Mi2 and Mi3, while the phenotype I2, with a major band (Rm: 1.1) and a minor and fainter band (Rm: 1.2), was detected in the other five Mi isolates (Table 1, Fig. $1 \mathrm{a}, \mathrm{b}$ ). The EST phenotype S2 (Rm: 0.9, 1.0) was detected in four isolates originally considered as Meloidogyne sp.1. The phenotype Hi3 (Rm: 1.1, 0.9, 0.8) is typical of M. hispanica and the phenotype S2a (Rm: 1.1, 0.9) was detected in the two Meloidogyne sp.2 isolates from Martinique (Table 1, Fig. 1c-e).

Two distinct MDH phenotypes were detected being the N1 phenotype (Rm: 1.0) associated with all isolates of M. incognita, Meloidogyne sp.1, M. hispanica and $M$. javanica and the phenotype N3 (Rm: 1.0, 1.1, 1.2) with Meloidogyne sp.2 isolates (Fig.1f-g).

Biological studies

\section{Cytogenetics}

All the 17 isolates of Meloidogyne spp. reproduced by mitotic parthenogenesis. Two chromosomal forms were recognised in these isolates. One form has $2 n=$ 32-36 chromosomes and is considered to be diploid and typical of $M$. hispanica. The triploid form $(3 \mathrm{n}=$ 40-46) was common in all isolates of $M$. incognita and the Meloidogyne sp.1 and Meloidogyne sp.2 isolates (Table 1).

\section{Differential host tests}

The M. incognita and Meloidogyne sp.1 isolates reproduced on tomato 'Rutgers', watermelon 'Charleston Gray' and pepper 'Early California Wonder', but they varied in their response to tobacco 'NC95' and cotton 'Deltapine 16'. Isolates 1, 8 and 12 did not reproduce on tobacco and cotton; isolates 2, 7 and 9 reproduced on tobacco but not on cotton; isolates $3,4,6,10$ and 11 reproduced on cotton but not on tobacco; isolate 5 reproduced on cotton and tobacco (Table 1). According to the 'North Carolina Host Test', Mi and Msp1 isolates: 1, 8 and 12, 2, 7 and 9, 3, 4, 6, 10 and 11 , and 5 belong to race $1,2,3$ and 4 , respectively. $M$ sp 2 isolates presented a host-range response similar of M. incognita race 2 (Table 1).

\section{Biometrical studies}

\section{Females}

The eight Mi and four Msp.1 isolates presented perineal patterns characteristic of $M$. incognita, with some variability. The dorsal arch was high and squarish with finely spaced, wavy striae; some had lateral wings and distinct forking near the lateral lines. Triangular postanal whorl and often with transverse striae that tended to be toward the vulva (Mi, Msp.1). The perineal patterns of Msp.2 isolates were elongated to ovoid, dorsal arch flattened to high sometimes squarish, striae widely spaced. Lateral fields rarely presented broken striae on both sides. Tail tip well defined, with few striae. Perivulval region not striated few striae near lateral edges of vulva. Phasmid small, ducts distinct within the cuticle, surface structure not apparent (Fig. 2). Perineal patterns of $M$. hispanica were similar to those of the original description (Hirschmann 1986). The stylet lengths of females were very similar among the Mi and Msp.1 isolates (14-19 $\mu \mathrm{m})$, as well as the distance of dorsal esophageal gland orifice (DGO, 3-5 $\mu \mathrm{m}$ ). The shape of the stylets was also similar; the cone was sharply pointed and distinctly curved dorsally; the shaft was slightly wider at the base; and the stylet knobs broadly elongate, sometimes anteriorly indented, and set off from the shaft (Fig. $3 \mathrm{a}-\mathrm{c}$ ). The Msp.2 isolates presented a robust 


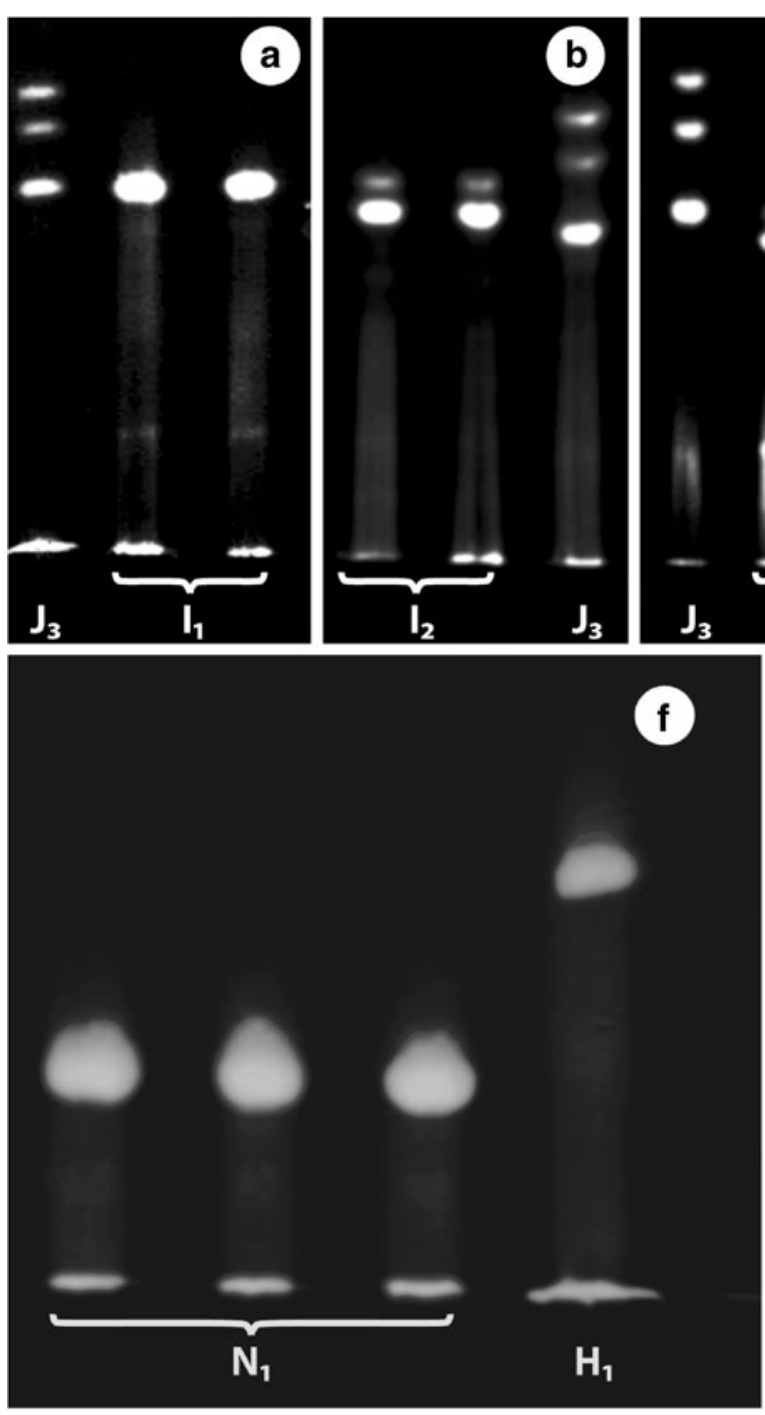

Fig. 1 Esterase (a, b, c, d, e) and malate dehydrogenase (f, $\mathbf{g})$ phenotypes of Meloidogyne spp. isolates. I1 and I2 - M. incognita; $\mathrm{S} 2$-Meloidogyne sp.1 (= M. incognita); S2a-Meloidogyne sp.2;

stylet $(15-16 \mu \mathrm{m})$ widening gradually posteriorly, cone tip straight, shaft cylindrical, narrower near junction with cone, knobs round pear-shaped and posteriorly sloping without indentations and DGO 4.0-4.5 $\mu \mathrm{m}$ (Fig. 3d).

In $M$. hispanica the stylet (13.6-14.6 $\mu \mathrm{m})$ cone was only slightly curved dorsally as in the species description (Hirschmann 1986). The distance of dorsal esophageal gland orifice (DGO) from the stylet base was 2.8$4.0 \mu \mathrm{m}$. All other female characters (Eisenback and Hunt 2009) were very similar to the description given by Hirschmann (1986).
Hi3-M. hispanica; J3-M. javanica (reference isolate); N1- $M$. incognita, M. hispanica and $M$. javanica, respectively; N3Meloidogyne sp.2; H1-M. hapla (reference isolate)

Males

The shape of the male anterior region of $M$. incognita studied in this paper was a useful diagnostic character for the isolates (I1N1, I2N1): the labial disc was rounded distinctly raised above the medial lips and may be centrally concave and marked by 3-6 incomplete annulations with number varying within and among isolates (Fig. $4 \mathrm{a}-\mathrm{c}$ ). In the Msp.1 and Msp.2 isolates, the labial disk and medial lips form a continuous head cap. Lateral lips were usually absent and only occasionally marked by short lines. The head 
Fig. 2 Light microscope photographs of perineal patterns of females of Meloidogyne spp. isolates: $\mathbf{a}-M$. incognita (I1N1); b-M. incognita (I2N1); c-Meloidogyne sp.1 (= M. incognita, S2N1); d-Meloidogyne sp.2. (S2aN3)
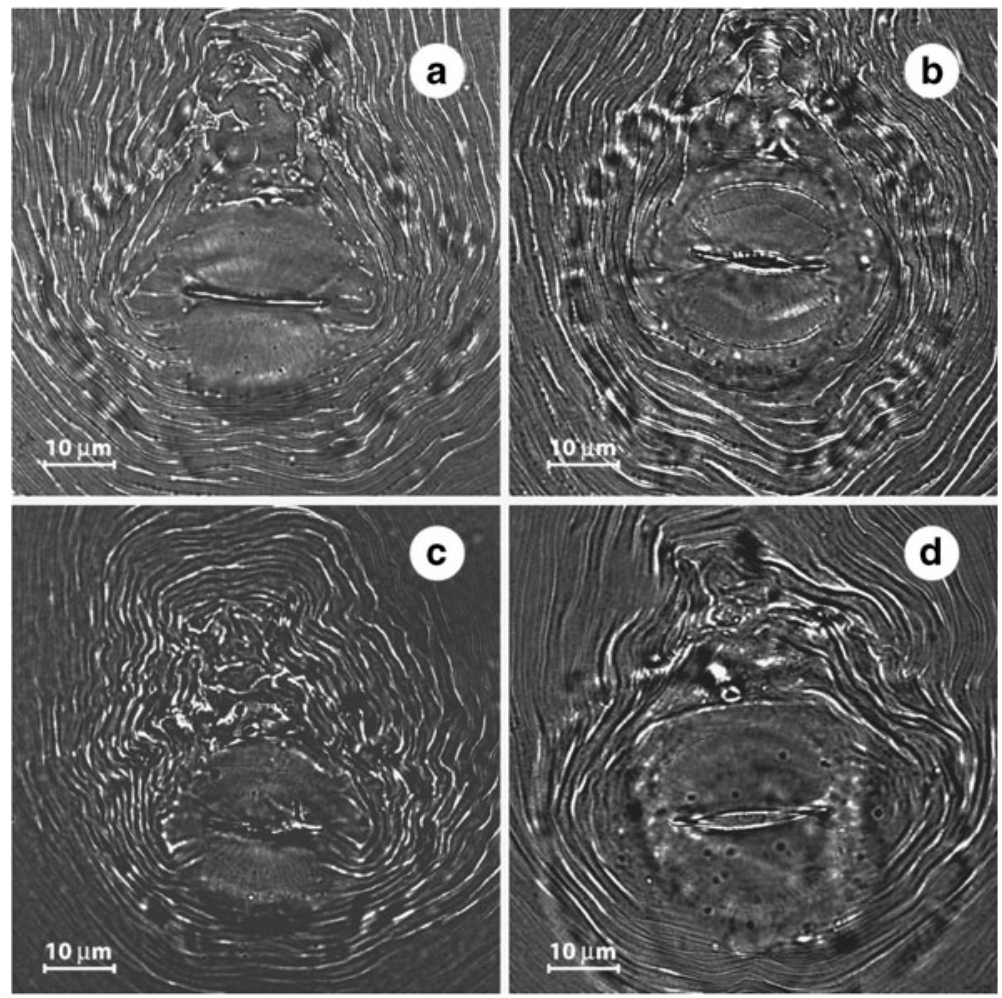

region was usually elevated and sometimes subdivided by incomplete head annulations (Fig. 4d), similar to M. hispanica (Hirschmann 1986).

The stylets varied in length: 24-25 $\mu \mathrm{m}$ long (Mi), 20-25 $\mu \mathrm{m}$ (Msp1), 18-22 $\mu \mathrm{m}$ (Msp.2) and 22-24 $\mu \mathrm{m}$ (Mhi). The shapes were very similar for the populations (I1N1, I2N1, S2N1), the tip was blunt and wider than the medial portion of the cone; the shaft was cylindrical and often narrowed near the knobs; and the knobs were set off from the shaft, anteriorly indented and broadly elongate to round. The DGO was relatively short $(1.5-3.5 \mu \mathrm{m})$. The stylet of the Msp2 isolates had a straight pointed cone, gradually increasing in diameter posteriorly, cylindrical shaft, rounded knobs, slightly set off from shaft, sloping posteriorly (Fig. 5a). The DGO was $2.0-4.5 \mu \mathrm{m}$ and $1.5-3.5 \mu \mathrm{m}$ in Msp.2 and M. hispanica, respectively.

\section{Second-stage juveniles (J2)}

The Mi and Msp.1 isolates presented the total body length, tail length and hyaline tail terminus in the range described for $M$. incognita: 346-463 $\mu \mathrm{m}, 42-$ $63 \mu \mathrm{m}, 6-11 \mu \mathrm{m}$. Only the hyaline tail terminus of the Msp. 2 isolates was higher: $14.0-17.0 \mu \mathrm{m}$. The stylet length, head end to stylet base and DGO of all isolates were close to the measurements described for $M$. incognita and M. hispanica: 10.0-14.0 $\mathrm{m}, 12.0-$ $15.0 \mu \mathrm{m}, 2.0-3.5 \mu \mathrm{m}$, respectively (Eisenback and Triantaphyllou 1991; Hirschmann 1986). The tail tip was rounded to pointed and the hyaline tail terminus was well defined in al populations of Mi, Msp1 and Msp2, but indistinct in M. hispanica. In SEM, the labial disc and medial lips were dumbbell-shaped in face view, and the labial disc was rounded and raised above the medial lips. The lateral lips were rounded to triangular and may fuse with the head region. The head region was marked with incomplete annulations (2-7) in the Mi and Msp.1 isolates (Fig. 5c). All other J2 characters were very similar to the description made by Eisenback and Triantaphyllou (1991). The head region of the Msp.2 isolates was smooth, occasionally with 1-2 short broken annulations (Fig. 5b).

\section{Molecular studies}

One fragment of 1,200 bp, $399 \mathrm{bp}$ and $955 \mathrm{bp}$ was obtained for $M$. incognita (I1N1 or I2N1), and Meloidogyne sp.1 isolates ( $\mathrm{S} 2 \mathrm{~N} 1)$ using the primers incB06F/R, incK $14 \mathrm{~F} / \mathrm{R}$ and $\mathrm{miF} / \mathrm{R}$, respectively 
Fig. 3 Scanning Electron Microscopy (SEM) photographs of stylet of different isolates of Meloidogyne spp. females: a-M. incognita (I1N1), b-M. incognita (I2N1), c-Meloidogyne sp.1 (= M. incognita, S2N1); d-Meloidogyne sp.2 (S2aN3)
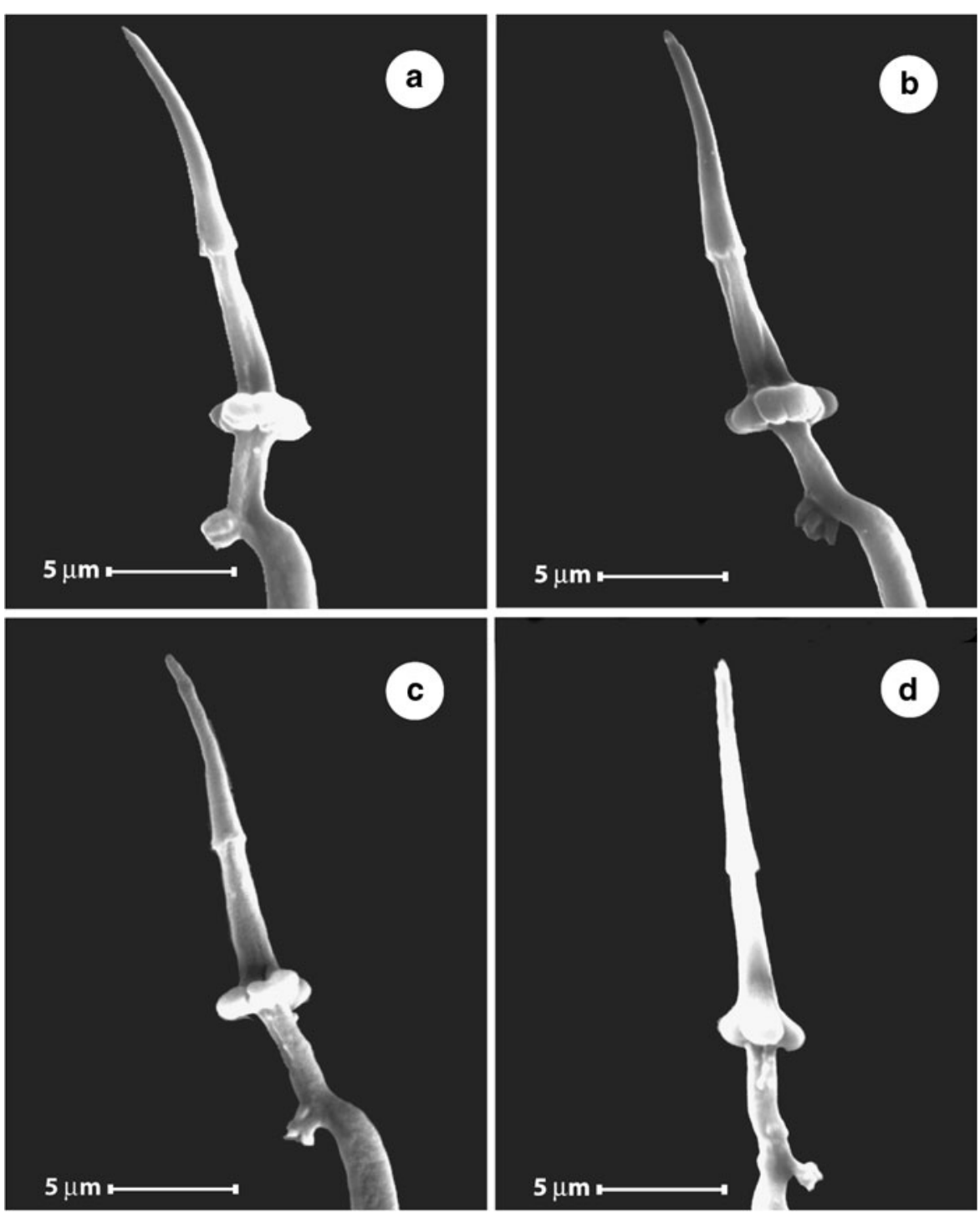

(Fig. 6a-c). None of these three specific fragments were amplified for the Meloidogyne sp.2 (S2aN3) and M. hispanica (Hi3) isolates (Fig. 6a-c). However, using the primer $\mathrm{miF} / \mathrm{R}$ a fragment of approximately $1,650 \mathrm{bp}$ was obtained for the $M$. hispanica isolates (Fig. 6c).

The genetic variability of the Meloidogyne spp. isolates used in this study was analysed using the RAPD and ISSR techniques. With the 35 random primers used in the RAPD analysis, the number of reproducible amplified fragments (replicated twice) varied from 10 to 20 per primer and per isolate, and their size ranged from 200 to $4500 \mathrm{bp}$. Over the whole experiment, 555 fragments were amplified and scored as RAPD markers. The ISSR primers allowed the amplification of 114 reproducible fragments, whose size ranged from 200 to $1000 \mathrm{bp}$. All the scorable amplified bands from RAPD and ISSR analyses were recorded to build $0-1$ matrices, on which phylogenetic analyses were performed. The global results of the rate of polymorphism observed in RAPD and ISRR fragments are provided in Table 2.

For the three main $M$. incognita (I1/N1 and I2/N1) isolates 517 fragments were amplified and the proportion of polymorphisms amplified ranged from 13.0$21.3 \%$. Considering now the three phenotypes I1/N1, $\mathrm{I} 2 / \mathrm{N} 1$ and $\mathrm{S} 2 / \mathrm{N} 1$ the polymorphism was $33 \%$ (Table 2). Among the three M. hispanica isolates the polymorphism was $9.9 \%$ and between $M$. hispanica (Hi3/N1) and Meloidogyne sp.2 (S2a/N3) it was $35 \%$. 

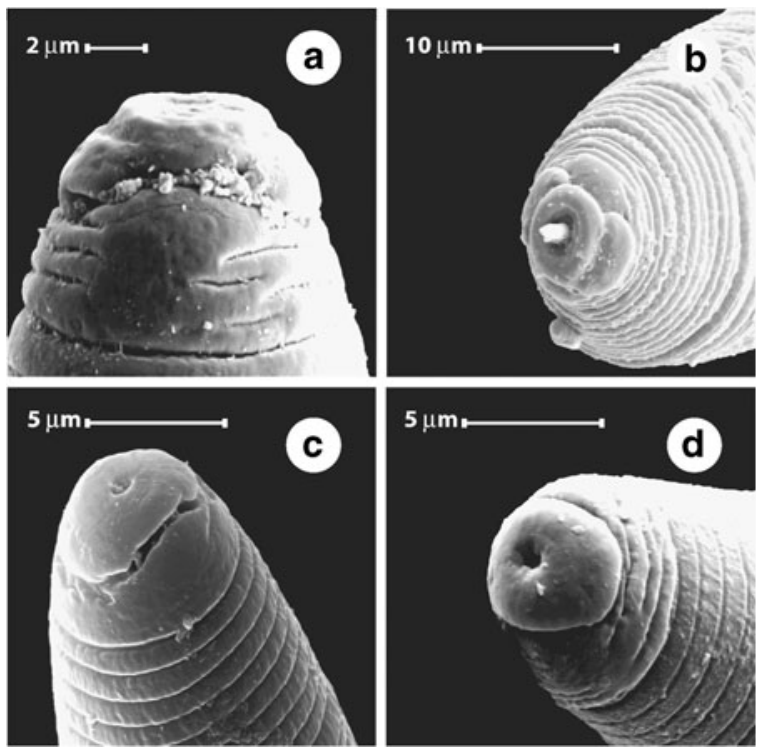

Fig. 4 Scanning Electron Microscopy (SEM) photographs of anterior region of male of different isolates of Meloidogyne spp: a-M. incognita (I1N1), b-M. incognita (I2N1); c-Meloidogyne sp. 1 (= M. incognita, S2N1); d-Meloidogyne sp. 2 (S2aN3)

Phylogenetic analyses of the ISSR and RAPD matrices (both separately and combined) using UPGMA, Maximum Parsimony and Bayesian inference gave the same general topology with respect to relationships among species and clustering of undescribed isolates with known species. Therefore, only the tree reconstructed by the Bayesian inference approach performed on the combined data set is exhibited (Fig. 7). The analysis identified two strongly supported monophyletic clades [Bayesian posterior probability $(\mathrm{PP})=1]$. In clade I $M$. hispanica isolates clustered together with the two atypical Meloidogyne sp.2 isolates $(\mathrm{PP}=1)$. In clade II the eight $M$. incognita isolates clustered together with the Meloidogyne sp.1 isolates (Fig. 7). Within clade II, the Meloidogyne sp.1 isolates Msp.1 (9), Msp.1 (10) and Msp.1 (11) clustered together $(\mathrm{PP}=0.99)$ (Fig. 7). The tree topology showed that most isoenzymatic phenotypes correspond to well-supported clusters (i.e., S2aN3, H3N1, I1N1, $\mathrm{S} 2 \mathrm{~N} 1$ ), while the I2N1 phenotype appeared shared by isolates belonging to two clusters of clade II. Conversely, the observed SCAR phenotypes perfectly matched with the two major clades identified (Fig. 7).

\section{Discussion}

The present biochemical, biometrical, cytological and molecular studies of eight isolates of $M$. incognita and four of Meloidogyne sp. 1 from Brazil revealed that the two esterase phenotypes (I1, I2) and the malate dehydrogenase phenotype (MDH: N1) are typical of $M$. incognita isolates, while $\mathrm{S} 2 / \mathrm{N} 1$ is an atypical and a new phenotype for this species. The two EST phenotypes, I2 and I1, were detected first by Carneiro et al. (2000; 2004); Cofcewicz et al. $(2004,2005)$ and identified as M. incognita. It is the first time that the four $\mathrm{S} 2 / \mathrm{N} 1$ isolates have been identified as variants of $M$. incognita, using morphological and molecular approaches. The occurrence of cryptic species with atypical phenotypes had previously been restricted to field surveys and the phenotypes were called: sp., S1, pII, S1, B1, B2 and S1 by Janati et al. (1982); Esbenshade and Triantaphyllou (1985); Fargette (1987); Castro et al. (2003); Cofcewicz et al. (2004); Carneiro et al. (2005a); Medina et al. (2006); respectively. M. hispanica exhibited the EST Hi3 phenotype described for this species (Hirschmann 1986) and the
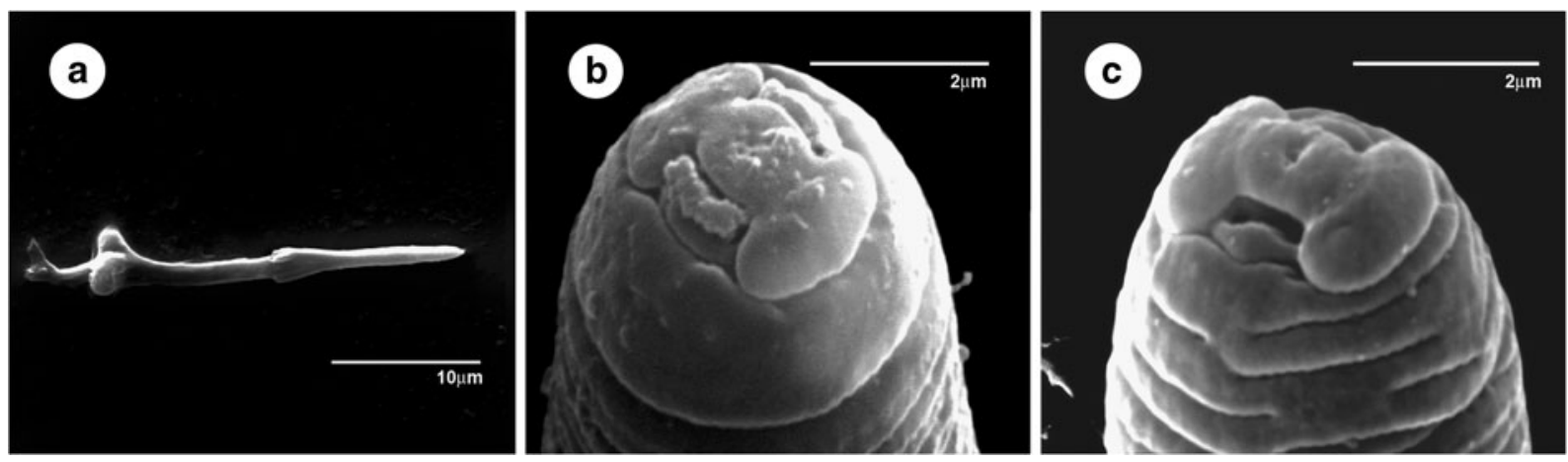

Fig. 5 Scanning Electron Microscopy photographs of: a-Stylet of male of Meloidogyne sp.2 (S2aN3), b-Anterior region of secondstage juvenile of Meloidogyne sp2 (S2aN3); c-Anterior region of second-stage juvenile of Meloidogyne sp. 1(= M. incognita, S2N1) 
Fig. 6 DNA amplification products of 18 isolates of Meloidogyne spp. using the M. incognita specific SCAR primers incB06F/R (a), incK $14 \mathrm{~F} / \mathrm{R}$ (b) and $\mathrm{miF} / \mathrm{R}$ (c) Lanes 1-3-M. incognita (I1N1); 4-8-M. incognita (I2N1); 9-12-Meloidogyne sp.1 (= M.incognita, S2N1); 13-14-Meloidogyne sp.2 (S2aN3); 15-17-M. hispanica $(\mathrm{Hi} 3 \mathrm{~N} 1) ; 18-M$. javanica (J3N1)
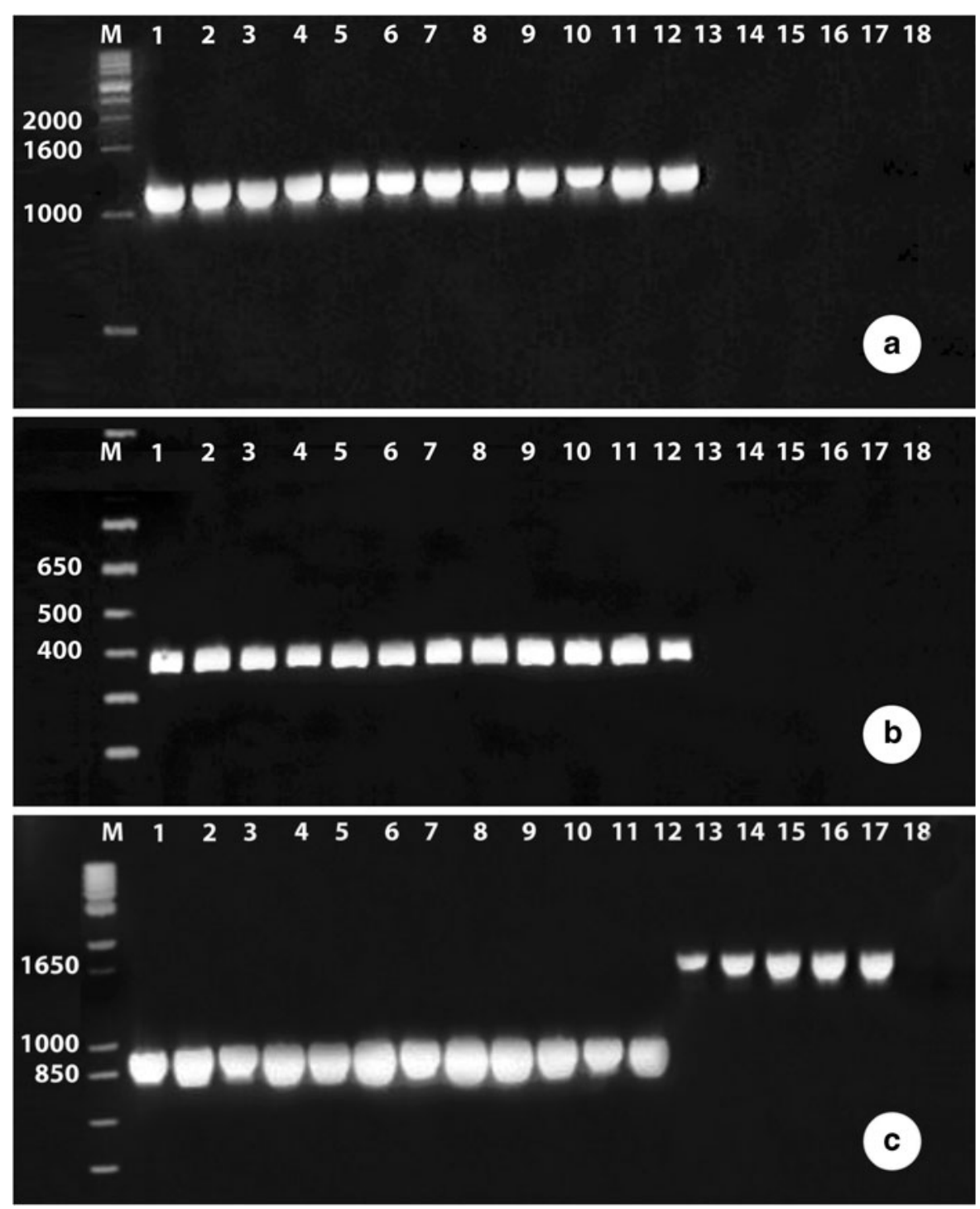

Msp2 from Martinique had the phenotype described for M. petuniae Charchar et al. 1999, but with a different MDH (Charchar et al. 1999).

The biometrical investigation carried out with the Mi and Msp1 isolates showed that these isolates were similar to $M$. incognita. The same was detected in populations of the following subspecies: $M$. incognita incognita, M. incognita grahami, $M$. incognita acrita and M. incognita wartellei (Hirschmann 1984). Although the majority of perineal patterns revealed typical features of $M$. incognita, considerable variation was observed both within and among isolates. Perineal pattern morphology cannot be considered as reliable and the identification of $M$. incognita populations should be supported by biochemical and/or molecular markers such as isozyme phenotypes or SCAR markers (Carneiro et al. 2004; Carneiro and Cofcewicz 2008). In fact, M. paranaensis, $M$. izalcoensis and $M$. inornata from coffee were erroneously associated with $M$. incognita on the basis of perineal pattern morphology (Carneiro et al. 1996; 2005a; 2008b).

In this study the stylet morphology of females of $M$. incognita was very similar among and within isolates and can be considered a species-specific character and these results agree with the observations made by Eisenback and Triantaphyllou (1991), but this character is not suitable for use in current diagnosis due the difficulty to excise and clean stylets for observation in SEM. Head morphology of males has also been recommended as a reliable taxonomic character for the 
Table 2 Rate of RAPD and ISSR polymorphisms observed at species level
Meloidogyne spp.

RAPD + ISSR fragments

Amplified Polymorphic

$(\%)$

M. incognita (I1/N1), isolates $1,2,3$

403

$62(15.4 \%)$

M. incognita (I2/N1), isolates 4, 5, 6, 7, 8

400

$52(13 \%)$

Meloidogyne sp.1 (=M.incognita), (S2/N1), isolates 9, 10, 11, 12450

$67(14.8 \%)$

M. hispanica $(\mathrm{H} 3 / \mathrm{N} 1)$, isolates $15,16,17$

$32(9.9 \%)$

Meloidogyne sp.2 (S2a/N3), isolates 13, 14

$39(13.8 \%)$

M. incognita (I1/N1, I2/N1), isolates $1,2,3,4,5,6,7,8$

$110(21.3 \%)$

M. incognita (I1/N1, S2/N1), isolates 1, 2, 3, 9, 10, 11,12

$132(23.9)$

M. incognita (I2/N1, S2/N1) isolates 4, 5, 6, 7, 8, 9, 10, 11, $12 \quad 533$

$120(22.5 \%)$

M. incognita (I1/N1, I2/N1, S2/N1), isolates $1,2,3,4,5,6,7, \quad 652$

$215(33 \%)$

$8,9,10,11,12$

M. hispanica (H3/N1), isolates 15, 16, 17 and Meloidogyne sp.2 383

$134(35 \%)$

$(\mathrm{S} 2 \mathrm{a} / \mathrm{N} 3)$, isolates 13,14

identification of Meloidogyne spp. (Eisenback and Triantaphyllou 1991). Males of isolates I1N1 and I2N1 were characterised as typical $M$. incognita, but the $\mathrm{S} 2 \mathrm{~N} 1$ isolates presented male head different from that previously described. These variations are consistent with the observations made by Eisenback and Triantaphyllou (1991) for some variants of M. incognita populations. In SEM, the stylets of the males (I1N1, I2N1, S2N1) were very similar in size and shape and similar to the description given by Eisenback and Triantaphyllou (1991). The stylet of the Msp2 isolates was different in shape from $M$. hispanica and M. incognita and similar to M. petuniae (Charchar et al. 1999)
Cytological analysis revealed the occurrence of a most common triploid form $(3 n=42-46)$, and agrees with the observations made by Triantaphyllou (1985a), that it is the most common and is widely distributed around the world. The diploid form $(2 n=32-36)$ appeared only in $M$. hispanica, a species closely related in morphology to M. incognita (Landa et al. 2008).

The North Carolina Host Differential test (Hartman and Sasser 1985) was conducted only to determine the physiological variability of $M$. incognita isolates. The four races of M. incognita were identified in 12 isolates. The identification of races in root-knot nematodes is very important for the characterisation of resistance in genetic and management programs in infested areas
Fig. 7 Bayesian phylogenetic tree from combined ISSR and RAPD data for known and unidentified Meloidogyne spp. isolates. Bold numbers at the end of each branch represent population codes as listed in Table 1. Numbers next to nodes indicate Bayesian posterior probabilities. The red dots indicate the two monophyletic clades. Columns on the right illustrate the isozymatic and SCAR (1- miF/R; 2- incB06F/R; 3- incK14F/R) phenotypes of the isolates
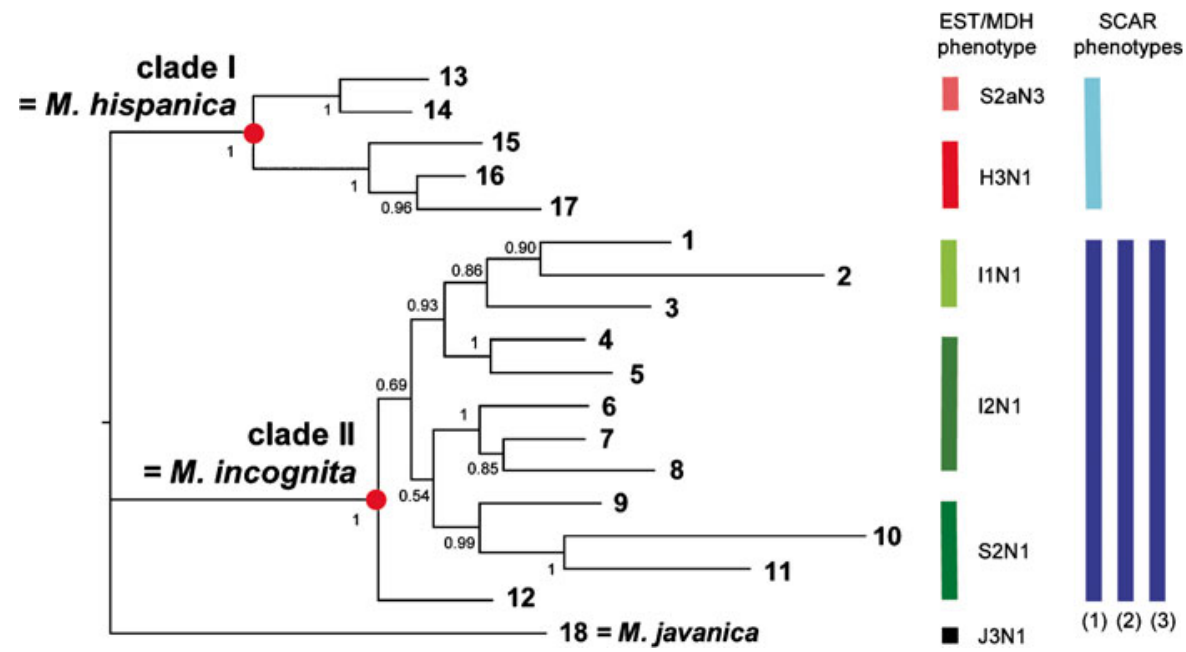
(Fassuliotis 1985; Castro et al. 2003). Although race determination is important in practice, Moens et al. (2009) recommended discontinuation of the terminology, especially as this concept has never been universally accepted because it measures a very restricted portion of the potential variation in parasitic variability. In our study no relationship was observed among races, enzymatic phenotypes and genetic polymorphisms. These findings suggested that for $M$. incognita, races do not have a genetic determinism (Carneiro and Cofcewicz 2008). The low molecular polymorphism found in this study among Mi and Msp.1 isolates was in agreement with previous RAPD analysis, and is also congruent with the isoenzymatic variability for these isolates (Cenis 1993; Castagnone-Sereno et al. 1994; Randig et al. 2002; Cofcewicz et al. 2004, 2005). Moreover, the clustering of the Mi and Msp.1 in one strongly supported monophyletic clade II confirmed that the four cryptic Msp1 isolates can be considered as M. incognita. Low molecular variability was also observed between M. hispanica and the two cryptic Msp.2 isolates (clade I). Low molecular variability was observed also in other parthenogenetic species that presented only one EST and $\mathrm{MDH}$ phenotypes like $M$. enterolobii (Tigano et al. 2010) or M. javanica (Cofcewicz et al. 2004). Other mitotic parthenogenetic species like $M$. arenaria presented high molecular variability and can be considered species swarms (Carneiro et al. 2008a).

Although M. hispanica and Msp.2 isolates clustered together within a strongly supported monophyletic clade, some morphological differences were observed on the perineal patterns, female and male stylets, J2 tail terminus, number of chromosomes and EST/MDH phenotypes. The Msp.2 isolates revealed similar esterase phenotype, perineal pattern morphology, male stylet, anterior region of males and $\mathrm{J} 2$, and number of chromosomes similar to $M$. petuniae (Charchar et al. 1999), but some differences can be also observed: female stylet knobs and female DGO and MDH phenotype. Considering all approaches studied in this paper, the results indicated that Msp.2 isolates were probably a new or unidentified species closely related to $M$. hispanica.

The SCAR markers developed for $M$. incognita allowed the amplification of specific fragments for Mi and Msp.2 isolates with different EST phenotypes. Our data validated the use of these markers as a molecular identification tool, considering that the previous results had been obtained for a limited number of isolates from different countries (Zijlstra 2000; Randig et al. 2002; Meng et al. 2004). SCAR markers have been developed to discriminate the three major root knot nematode species, $M$. incognita, $M$. javanica and $M$. arenaria, occurring in neotropical and temperate areas or in protected crop systems (Zijlstra 2000; Zijlstra et al. 2000; Fourie et al. 2001).

The SCAR primers inc-K14-F/R, ex-D-15 R/F and par-C09-F/R were also developed for the Brazilian coffee-damaging species $M$. exigua, M. paranaensis and M. incognita (Randig et al. 2002). These primers were used in multiplex PCR in a single reaction to identify 54 populations of Meloidogyne spp. from coffee plantations in Brazil, allowing the unambiguous differentiation of the species alone or in mixtures, and its potential for application in routine diagnosis has been confirmed (Carneiro et al. 2005b).

Acknowledgements This work was funded by Consórcio Brasileiro de Pesquisa e Desenvolvimento do Café, Embrapa and Conselho Nacional de Pesquisa (CNPq).

\section{References}

Blok, V. C., \& Powers, O. (2009). Biochemical and molecular identification. In R. Perry, M. Moens, \& J. L. Starr (Eds.), Root-knot nematodes (pp. 98-118). Cambridge: CAB International.

Blok, V. C., Phillips, M. S., McNicol, J. W., \& Fargette, M. (1997). Genetic variation in tropical Meloidogyne spp. as shown by RAPDs. Fundamental and Applied Nematology, 20, 127-133.

Carneiro, R. M. D. G., \& Almeida, M. R. A. (2001). Técnica de eletroforese usada no estudo de enzimas dos nematóides de galhas para identificação de espécies. Nematologia Brasileira, 25, 555-560.

Carneiro, R. M. D. G., \& Cofcewicz, E. T. (2008). Taxonomy of coffee-parasitic root-knot nematodes, Meloidogyne spp. In R. M. Souza (Ed.), Plant parasitic nematodes of coffee (pp. 87-122). New York: Springer.

Carneiro R. M. D. G., Carneiro, R. G., Abrantes, I. M. de O., Santos M. S. N. de A., \& Almeida, M. R. A. (1996). Meloidogyne paranaensis n. sp. (Nemata: Meloidogynidae) a root-knot nematode parazitizing coffee from Brazil. Journal of Nematology, 28, 177-189.

Carneiro, R. M. D. G., Almeida, M. R. A., \& Quénéhervé, P. (2000). Enzyme phenotypes of Meloidogyne spp. populations. Nematology, 2, 645-654.

Carneiro, R. M. D. G., Tigano, M. S., Randig, O., Almeida, M. R. A., \& Sarah, J. L. (2004). Identification and genetic diversity of Meloidogyne spp. (Tylenchida: Meloidogynidae) on coffee from Brazil, Central America and Hawaii. Nematology, 6, $37-47$. 
Carneiro, R. M. D. G., Almeida, M. R. A., Gomes, A. C. M. M., \& Hernandez, A. (2005a). Meloidogyne izalcoensis n. sp. (Nematoda: Meloidogynidae), a root-knot nematode parasiting coffee in El Salvador. Nematology, 7, 819-832.

Carneiro, R. M. D. G., Randig, O., Almeida, M. R. A., \& Gonçalves, W. (2005b). Identificação e caracterização de espécies de Meloidogyne em cafeeiro nos Estados de São Paulo e Minas Gerais através dos fenótipos de esterase e SCAR-Multiplex-PCR. Nematologia Brasileira, 29, 233241.

Carneiro, R. M. D. G., Santos, M. F. A., Almeida, M. R. A., Mota, F. C., \& Tigano, M. S. (2008a). Diversity of Meloidogyne arenaria using morphological, cytological and molecular approaches. Nematology, 10, 819-834.

Carneiro, R. M. D. G., Mendes, M. L., Almeida, M. R. A., Santos, M. F. A., Gomes, A. C. M. M., \& Karssen, G. (2008b). Additional information on Meloidogyne inornata Lordello, 1956 (Tylenchida: Meloidogynidae) and its characterization as a valid species. Nematology, 10, 123-136.

Carneiro, R. M. D. G., Santos, D. F., Costa, S. B., Sousa, F. R., Almeida, M. R. A., Santos, M. F. A., Siqueira, K. M. S., Tigano, M. S., \& Fonseca, A. F. A. (2009). Reaction of 'Conilon' coffees to different populations of Meloidogyne spp. Nematologia Brasileira, 33, 311.

Castagnone-Sereno, P. (2006). Genetic variability and adaptative evolution in parthenogenetic root-knot nematodes. Heredity, 96, 282-289.

Castagnone-Sereno, P., Vanlerberghe-Masutti, F., \& Leroy, F. (1994). Genetic polymorphism between and within Meloidogyne species detected with RAPD markers. Genome, 37, 904-909.

Castro, J. M. C., Lima, R. D., \& Carneiro, R. M. D. G. (2003). Variabilidade isoenzimática de populações de Meloidogyne spp. de regiões brasileiras produtoras de soja. Nematologia Brasileira, 27, 1-12.

Cenis, J. L. (1993). Identification of four major Meloidogyne spp. by random amplified polymorphic DNA (RAPD-PCR). Phytopathology, 83, 76-80.

Charchar, J. M., Eisenback, J. D., \& Hirschmann, H. (1999). Meloidogyne petuniae n. sp. (Nemata: Meloidogynidae), a root-knot nematode parasitic on petunia in Brazil. Journal of Nematology, 31, 81-91.

Cofcewicz, E. T., Carneiro, R. M. D. G., Randig, O., Chabrier, C., \& Quénéhervé, P. (2005). Diversity of Meloidogyne spp. on Musa in Martinique, Guadeloupe and French Guiana. Journal of Nematology, 37, 313-322.

Cofcewicz, E. T., Carneiro, R. M. D. G., Castagnone-Sereno, P., \& Quénéhervé, P. (2004). Enzyme phenotypes and genetic diversity of root-knot nematodes parasitising Musa in Brazil. Nematology, 6, 85-95.

Eisenback, J. D., \& Hunt, D. J. (2009). General morphology. In R. Perry, M. Moens, \& J. L. Starr (Eds.), Root-knot Nematodes (pp. 18-54). Cambridge: CABI North America Ofice.

Eisenback, J. D., \& Triantaphyllou, H. H. (1991). Root-knot nematode: Meloidogyne spp. and races. In W. R. Nickle (Ed.), Manual of agricultural nematology (pp. 191-274). New York: Marcel Dekker.

Esbenshade, P. R., \& Triantaphyllou, A. C. (1990). Isozyme phenotypes for the identification of Meloidogyne species. Journal of Nematology, 22, 10-15.
Esbenshade, P. R., \& Triantaphyllou, A. C. (1985). Use of enzyme phenotypes for identification of Meloidogyne species (Nematoda: Tylenchida). Journal of Nematology, 17, 6-20.

Fargette, M. (1987). Use of esterase phenotype in the taxonomy of the genus Meloidogyne. 2. Esterase phenotypes observed in West African populations and their characterization. Révue de Nématologie, 10, 45-56.

Fassuliotis, G. (1985). The role of the nematologist on the development of resistant cultivars. In J. N. Sasser \& C. C. Carter (Eds.), An advanced treatise on Meloidogyne. Biology and control Vol. 1, (pp. 233-240). Raleigh: North Carolina State University Graphics.

Felsenstein, J. (1985). Confidence limits on phylogenies: an approach using the bootstrap. Evolution, 39, 783-791.

Fourie, H., Zijlstra, C., \& McDonald, A. H. (2001). Identification of root-knot nematode species occurring in South Africa, using the SCAR-PCR technique. Nematology, 3, 675-80.

Hartman, R. M., \& Sasser, J. N. (1985). Identification of Meloidogyne species on the basis of differential host test and perineal pattern morphology. In K. R. Barker, C. C. Carter, \& J. N. Sasser (Eds.), An advanced treatise on Meloidogyne. Vol. 2, Methodology (pp. 69-77). Raleigh: North Carolina State University Graphics.

Hirschmann, H. (1986). Meloidogyne hispanica n. sp. (Nematoda: Meloidogynidae) the 'Seville Root-Knot Nematode'. Journal of Nematology, 18, 520-532.

Hirschmann, H. (1984). Morphological variability of Meloidogyne incognita revealed by light and scanning microscopy. Proceedings of the 1st International Congress of Nematology. (pp.35). Guelph, Ontario, Canada.

Janati, A. A., Bergé, A., Triantaphyllou, A. C., \& Dalmasso, A. (1982). Nouvelles données sur 1' utilisation des isoestérases pour l' identification des Meloiodogyne. Révue de Nématologie, 5, 147-154.

Karssen, G., \& Moens, M. (2006). Root-knot nematodes. In R. L. Perry \& M. Moens (Eds.), Plant nematology (pp. 5990). Wallingford: CABI Publishing.

Landa, B. B., Palomares Rius, J. E., Vovlas, N., Carneiro, R. M. D. G., Maleita, C. M. N., Abrantes, I. M. de O., \& Castillo, P. (2008). Molecular characterization of Meloidogyne hispanica (Nematoda, Meloidogynidae) by phylogenetic analysis of genes within the rDNA in Meloidogyne spp. Plant Disease, 92, 1104-1110.

Lax, P., Dueñas, J. C. R., Gardenal, C. N., \& Doucet, M. E. (2007). Assessment of genetic variability in populations of Nacobbus aberrans (Thorne, 1935) Thorne \& Allen, 1944) Nematoda: Pratylenchidae) from Argentina. Nematology, 9, 261-270.

Medina, I. L., Gomes, C. B., Rossi, C., \& Carneiro, R. M. D. G. (2006). Characterization and identification of root-knot nematodes (Meloidogyne spp.) from fig trees in Rio Grande do Sul and São Paulo States of Brazil. Nematologia Brasileira, 30, 179-187.

McClure, M., Kruk, T. H., \& Migashi, I. (1973). A method for obtaining quantities of clear Meloidogyne eggs. Journal of Nematology, 5, 230.

Meng, Q. P., Long, H., \& Xu, J. H. (2004). PCR assays for rapid and sensitive identification of three major root-knot nematodes, Meloidogyne incognita, M. javanica and M. arenaria. Acta Phytopathologica Sinica, 34, 2004-2010. 
Moens, M., Perry, R. N., \& Starr, J. L. (2009). Meloidogyne Species - a diverse group of novel and important plant parasites. In R. N. Perry, M. Moens, \& J. L. Starr, (Eds.), Root-knot Nematodes, (pp. 1-17). Cambridge: CABI North America Office.

Muniz, M. F. S., Campos, V. P., Moita, A. W., Gonçalves, W., Almeida, M. R. A., Sousa, F. R., \& Carneiro, R. M. D. G. (2009). Reaction of coffee genotypes to different populations of Meloidogyne spp.: detection of a naturally virulent M. exigua population. Tropical Plant Pathology, 34, 370378.

Oliveira, D. S., Oliveira, R. D. L., \& Gonçalves, W. (2006). Fenótipo S1 de esterase em Meloidogyne incognita no Brasil. Fitopatologia Brasileira, 31, 207.

Randig, O., Bongiovanni, M., Carneiro, R. M. D. G., \& Castagnone-Sereno, P. (2002). Genetic diversity of rootknot nematodes from Brazil and development of SCAR markers specific for the coffee-damaging species. Genome, $45,862-870$.

Ronquist, F., \& Huelsenbeck, J. P. (2003). MrBayes 3: Bayesian phylogenetic inference under mixed models. Bioinformatics, 19, 1572-1574.

Semblat, J. P., Wajnberg, E., Dalmasso, A., Abad, P., \& Castagnone-Sereno, P. (1998). High-resolution DNA fingerprinting of parthenogenetic root-knot nematodes using AFLP analysis. Molecular Ecology, 7, 119-125.

Swofford, D. L. (2002). PAUP*. Phylogenetic analysis using UPGMA (*and other methods). Version 4 b10. Sinauer Associates, Sunderland, Massachusetts.

Taylor, D. P., \& Netscher, C. (1974). An improved technique for preparing perineal patterns of Meloidogyne spp. Nematologica, 20, 268-269.
Tigano, M., Siqueira, K., Castagnone-Sereno, P., Mulet, K., Queiroz, P., Santos, M., Teixeira, C., Almeida, M., Silva, J., \& Carneiro, R. (2010). Genetic diversity of the root-knot nematode Meloidogyne enterolobii and development for SCAR marker for this guava-damaging species. Plant $\mathrm{Pa}$ thology, 59, 1054-1061.

Tigano, M. S., Carneiro, R. M. D. G., Jeyaprakash, A., Dickson, D., \& Adams, B. J. (2005). Phylogeny of Meloidogyne spp. based on 18S rDNA and the intergenic region of mitochondrial DNA sequences. Nematology, 7, 851-862.

Triantaphyllou, A. C. (1985a). Cytogenetics, cytotaxonomy and phylogeny of root-knot nematodes. In K. R. Barker, C. C. Carter, \& J. N. Sasser (Eds.), An advanced treatise on Meloidogyne, vol. 1, biology and control (pp. 113-126). Raleigh: North Carolina State University Graphics.

Triantaphyllou, A. C. (1985b). Cytological methods for the study of oogenesis and reproduction of root-knot nematode. In K. R. Barker, C. C. Carter, \& J. N. Sasser (Eds.), An advanced treatise on meloidogyne, vol. 2, methodology (pp. 107-114). Raleigh: North Carolina State University Graphics.

Triantaphyllou, A. C. (1981). Oogenesis and the chromosomes of the parthenogenetic root-knot nematode Meloidogyne incognita. Journal of Nematology, 13, 95-104.

Zijlstra, C. (2000). Identification of Meloidogyne chitwoodi, M. fallax and M. hapla based on SCAR-PCR: a powerful way of enabling reliable identification of populations or individuals that share common traits. European Journal of Plant Pathology, 106, 283-290.

Zijlstra, C., Donkers-Venne, D. T. H. M., \& Fargette, M. (2000). Identification of Meloidogyne incognita, M. javanica and $M$. arenaria using sequence characterised amplified regions (SCAR) based PCR assays. Nematology, 2, 847-53. 